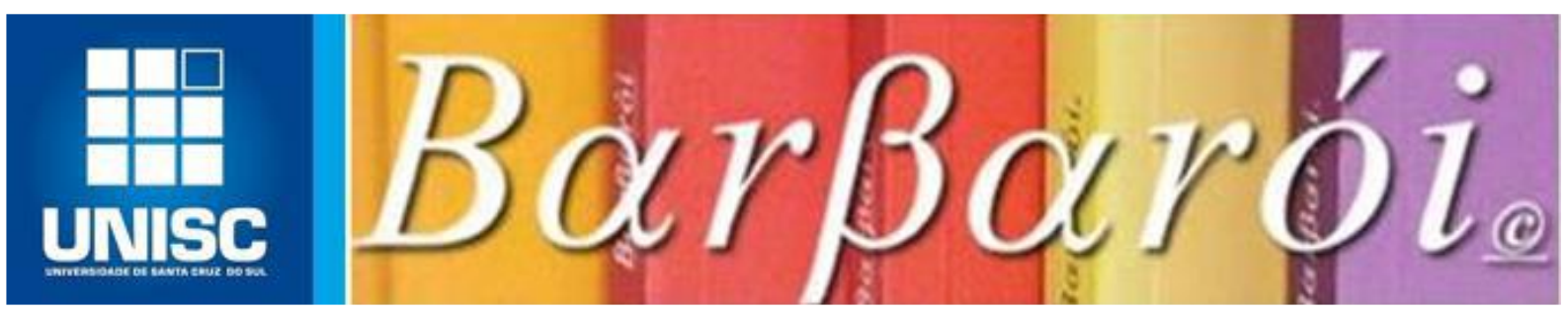

\title{
O ENSINO COMO PESQUISA E O DESENVOLVIMENTO DA AUTORREGULAÇÃO NA EDUCAÇÃO SUPERIOR: UM ESTUDO NA GRADUAÇÃO DE SERVIÇO SOCIAL
}

DOI: http://dx.doi.org/10.17058/barbaroi.v0i57.6407

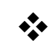 \\ Maria Luisa Bissoto \\ Brasil \\ Maria Isabel Vicente \\ Centro Universitário Salesiano de São Paulo - UNISAL - Brasil

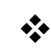

\section{Resumo}

O objetivo do estudo é avaliar se o alinhamento entre ensino e pesquisa, como didaticamente proposto no âmbito de um curso de graduação em Serviço Social, vem trazendo contribuições para dois componentes fundamentais a aprendizagens acadêmicas e profissionais bem sucedidas: a autorregulação e a motivação. Metodologicamente, busca-se estabelecer comparações entra as características dessa proposição didática e um modelo cíclico de autorregulação da aprendizagem, empregando-se como instrumento de coleta de dados um questionário semiestruturado, aplicado aos alunos do referido curso. Como resultados, consideramos que é possível afirmar que o desenvolvimento de metodologias didáticopedagógicas fundadas na associação ensino e pesquisa mostrou-se relevante para que os alunos elaborassem estratégias cognitivas para gerir, interpretar e organizar a informação, colaborou para uma melhor administração do tempo dispendido para as atividades acadêmicas, mobilizou a consciência quanto à construção da identidade profissional, influenciando na determinação em concluir os estudos e a na motivação para ser bem sucedido. Destacamos a importância que o grupo exerce sobre o desenvolvimento da autorregulação e da motivação, aspectos que podem ser mais aprofundados nas discussões sobre novas metodologias para a Educação Superior.

Palavras-chave: Autorregulação. Educação superior. Ensino como pesquisa.

\section{Introdução}

A vinculação entre ensino e pesquisa tem sido concebida como tarefa da Universidade no Brasil desde a LDB de 1968, sendo reforçada nas legislações educacionais subsequentes, na Constituição de 1998, em referência à autonomia das instituições de Educação Superior, no Plano Nacional de Educação de 2001 e, mais recentemente, também naquele sancionado em 
junho de 2014, pela Presidência da República (GUEDES, MURANAKA, ARAGÃO, 2013; CURY, 2010; BRASIL, 2014). Contudo, o alinhamento entre ensino e pesquisa como estratégia didático-metodológica para aprimorar a qualidade educacional nesse nível de ensino começou a adquirir relevância somente a partir da década de 1990.

$\mathrm{Na}$ literatura se encontram dados de que o alinhamento metodológico entre ensino e pesquisa se constitui como um diferencial importante para o aprimoramento da formação profissional e pessoal dos estudantes (GRIFFIOEN, GROEN, NAK, 2019; TIGHT, 2012; JENKINS, 2004). Dentre os ganhos apontados estão o desenvolvimento de competências para problematizar e investigar a realidade, de melhor conjugar teoria e prática, e de formar profissionais socialmente engajados e envolvidos com as questões do seu tempo. É fundamental, porém, que as metodologias de ensino baseadas nesta perspectiva sejam continuamente avaliadas, sob pena de fragilizarmos esta formação, caindo em um ensino que se reduza ao "saber-fazer", encampando ingenuamente os discursos neoliberais de "preparar para o trabalho", tratando os saberes próprios à Universidade meramente como técnicas instrumentalizadoras das ações humanas.

Cabe também atentar para os impactos das inovações didático-pedagógicas que podem estar associadas ao ensino como pesquisa, as quais tendem a favorecer num papel mais ativo dos estudantes universitários na aprendizagem, colaborando para o desenvolvimento de processos cognitivos complexos. Nesse sentido, destacam-se aqui os trabalhos de Zimmerman e Schunk (2011), que discute a autorregulação e a motivação dos estudantes da Educação Superior, de Miller e Dumford (2014), que analisam o pensamento criador, de Thompson (2014) voltados para os fatores que envolvidos nos processos de ensino-aprendizagem promoveriam o desenvolvimento neurocortical e, assim, os processos cognitivos de mais alta ordem, e aqueles de Ball e Perry (2010), que examinaram a relação entre os processos cognitivos dos estudantes universitários e seu engajamento no curso escolhido. Outros autores analisaram o impacto do ensino vinculado à pesquisa em outras áreas do desenvolvimento humano. Nesse sentido, Pessoa de Freitas, Montezano e Odelius (2019), investigaram como o envolvimento do estudante universitário, em várias modalidades de atividades acadêmicas, incluindo aquelas vinculadas à pesquisa e à investigação, e à participação em grupos de pesquisa, promoveram o desenvolvimento de competências organizacionais e de gerenciamento. Ehlers (2020), destaca como uma didática para o ensino superior, centrada em promover a imersão dos estudantes em cenários de aprendizagem que requerem formas de pensar complexas, como aquelas encontradas no fazer científico, se mostram propícias para o 
desenvolvimento da criatividade, das habilidades de auto-organização e de reflexão, assim como das competências sociais. Competências e habilidades que, segundo o autor, estão na base de outras, como aquelas de compreender e agir para a sustentabilidade e a justiça social, para gerir e conviver com as mudanças demográficas e com as implicações socioculturais e econômicas advindas dessas. Tais habilidades e competências são denominadas pelo autor como "future skills", ou seja, compõem aquelas presumidas para que possamos fazer frente aos desafios das décadas futuras.

Deve-se considerar, contudo, que ainda há vários nexos a serem ponderados para que a inter-relação ensino e pesquisa se constitua numa estratégia didático-metodológica mais largamente usada e bem sucedidamente empregada na Educação Superior. Dentre esses estão a "formatação" comportamental dos estudantes, mais acostumados a assumirem um papel passivo nas salas de aula, em virtude do longo processo de escolarização que antecede à Educação Superior, pautado em muito na acumulação de conteúdos e numa concepção de “educação bancária” (FREIRE, 1997), o desconhecimento que existe nos campos didáticos e epistemológicos sobre os tipos e níveis de conhecimentos e ações investigativas necessárias para a formação superior, e os modos de conceber ensino e pesquisa vigentes entre os pesquisadores e docentes, dos diversos campos do saber.

A experiência didática aqui relatada é resultante de uma proposição que privilegia a articulação entre o ensino e a investigação socialmente comprometida, desenvolvida num curso presencial de graduação em Serviço Social, na macrorregião de Campinas, interior do estado de São Paulo. Denominado aqui como "Projeto" do curso de Serviço Social, tal proposição foi delineada no âmbito das metodologias ativas de ensino, visando desenvolver, com os estudantes do referido curso, as competências para a investigação direcionada a temáticas formativa e socialmente relevantes, considerando-se a filosofia institucional e o projeto pedagógico do curso. Intentou-se, assim, que o discente passasse a pensar a construção do conhecimento "em ação", integrando os conteúdos das diversas disciplinas acadêmicas no enfrentamento de questões referentes ao campo profissional, promovendo a compreensão da natureza polissêmica e multifacetada do conhecimento. E que para a efetivação dos saberes nas Ciências Humanas e Sociais como promotores da qualidade de vida é necessário conceber a pesquisa como questionamento e problematização daquilo que nos aparece como "dado", como "natural", favorecendo a construção de outras realidades/verdades. Constitui-se, dessa forma, numa atividade fundamentalmente ética. 
Na proposição original, que o "Projeto" assumiu no curso de Serviço Social, dentre os anos de 2011-2018, a atividade investigativa iniciava-se no $1^{\circ}$ semestre de cada ano letivo, estendendo-se pelos três semestres subsequentes, sob a condução, preferencialmente, do mesmo professor-orientador. Partia-se de um tema gerador, que emergia de discussões e de escolhas feitas pela classe, a partir de problemáticas que se vinculassem ao campo de estudos do Serviço Social. Após a seleção do tema gerador havia a divisão desse em subtemas, de forma a contemplar temáticas mais específicas, de acordo com os interesses dos grupos de estudantes. A cada semestre os estudantes desenvolviam uma fase da pesquisa: exploratória e construção da problematização, revisão da literatura, coleta de dados de campo e elaboração de uma proposição explicativa, possibilidades de abordagem e/ou intervenção, na perspectiva do Serviço Social. Cabe também ressaltar que tal estrutura poderia sofrer algumas variações, em virtude de características do contexto da classe, do professor-orientador, etc. O "Projeto" era considerado uma atividade curricular, com a carga horária de duas horas aula semanais (110 minutos). Ao final de cada semestre os trabalhos desenvolvidos eram avaliados pelo professororientador por meio de relatórios parciais de pesquisa, bem como pela apresentação da pesquisa em andamento em eventos acadêmicos. Havia também uma auto-avaliação, realizada pelos próprios estudantes, em relação ao seu grupo de trabalho. Como resultado da avalição poderia ser atribuído a cada aluno até um ponto por semestre letivo, a ser acrescentado na média final das demais disciplinas.

O artigo em tela, analisando a proposta metodológica do "Projeto" acima citado, espera contribuir para o avanço das reflexões e para a construção do conhecimento referente a outras perspectivas didáticas para a Educação Superior, bem como os impactos que essas podem ter na formação profissional e pessoal dos discentes.

\section{Exposição do problema e Metodologia}

O objetivo da investigação realizada foi, mediante o já exposto, avaliar se o alinhamento metodológico entre ensino e pesquisa, como planejado no âmbito do "Projeto" do curso de Serviço Social, trouxe contribuições para dois componentes fundamentais a aprendizagens acadêmicas e profissionais bem-sucedidas: a autorregulação e a motivação.

Metodologicamente, para a coleta de dados, pedimos aos estudantes da turma de 2013 do curso de Serviço Social, que respondessem a um questionário semiestruturado, constituído por 5 questões fechadas, voltadas para a sondagem de percepções, complementadas por questões abertas, que visaram o esclarecimento e o desdobramento das respostas obtidas nas 
questões fechadas. Esse modelo de questionário baseou-se em Bernhardt (2013), que enfatiza a importância de se buscar conhecer, nas pesquisas realizadas em âmbito escolar, as concepções, crenças, impressões e julgamentos constituídos pelos estudantes em relação a tópicos particulares, envolvidos quer nas atividades didático-pedagógicas, quer no contexto escolar, nas formas de gestão ou outras, que influenciam o seu processo de aprendizagem e de desenvolvimento. Para tanto, e acompanhando o proposto pela autora acima referida, as questões fechadas foram construídas em forma de estamentos, e as opções das respostas deveriam ser marcadas numa escala de Likert. As questões abertas foram analisadas pelo referencial da análise do discurso, conforme proposto por Bryman (2008).

O questionário foi respondido voluntariamente e de forma anônima, na ausência de professores, por 21 dos estudantes, que no primeiro semestre de 2014, quando da aplicação do questionário, se encontravam no $3^{\circ}$ semestre do curso de Serviço Social, estando envolvidos com os processos de pesquisa do "Projeto" a aproximadamente um ano e meio. Esse número correspondeu a $80 \%$ do total de estudantes da classe. Dentre os respondentes havia 02 alunos do sexo masculino, sendo os demais do sexo feminino. A faixa etária predominante estava entre os 20 e os 28 anos (73\% dos respondentes) e nenhum respondente tinha formação universitária anterior. O tema gerador selecionado por essa turma foi a "violência contra a criança e o jovem", e os diversos grupos de pesquisa, formados pelos estudantes dessa turma, abordaram esta temática a partir dos seguintes subtemas: a pedofilia, a exploração sexual infanto-juvenil, a violência intrafamiliar/doméstica, aquela presente nos desenhos infantis, o bullying, o tráfico humano envolvendo crianças e jovens e a drogadição.

Com a aplicação do questionário buscou-se figurar uma representação dos discentes quanto ao desenvolvimento dos processos de autorregulação e de motivação, que estariam envolvidos nas situações de ensino como pesquisa propostas ao longo do referido projeto. Para a elaboração das questões foram empregadas as categorias trabalhadas por Zimmerman (2000), no escopo da teoria social cognitiva da aprendizagem, em relação à autorregulação e à motivação, a saber: análise da tarefa, crenças de automotivação, autocontrole, auto-observação, autojulgamento e auto-reação. Procurou-se conhecer também a influência exercida pelo grupo sobre estes componentes da aprendizagem, aqui analisados pelos estudos de Finkel e Fitzsimons (2011) e de Järvelä et. al. (2013).

As perguntas às quais se pretendeu responder com este estudo foram: 
a. As atividades realizadas no âmbito do "Projeto" mostraram-se efetivas para o desenvolvimento da autorregulação, pensada essa tanto no sentido da formação acadêmica como em relação às especificidades da "atitude/perfil profissional"?

b. O mesmo vale para o componente motivacional: a participação no "Projeto" mostrou ter contribuído para que os discentes se motivassem para o aprendizado acadêmico e profissional?

c. Quais as relações possíveis de serem estabelecidas entre o desenvolvimento dos processos de autorregulação e motivação e as dinâmicas sócio-interativas transcorridas nos grupos de discentes, ao longo da investigação?

\title{
Fundamentação Teórica
}

Antes de tratarmos da apresentação e análise dos dados propriamente ditos expomos, a seguir, algumas definições e conceitos sobre a autorregulação e a motivação. Para Baumeister, Vohs e Tice (2007) o termo autorregulação se refere ao processo pelo qual o self altera suas próprias respostas ou estados internos, de forma a direcionar-se para a consecução de objetivos e metas. Panadero e Alonso-Tapia (2014) conceituam a autorregulação como o controle que os estudantes exercem sobre seu próprio comportamento, cognição, emoções e motivações, fazendo uso de estratégias pessoais, direcionadas a atingir seus objetivos frente a determinadas tarefas e/ou expectativas. Zimmerman (2002, p. 65), na mesma linha, assim define a autorregulação:

\begin{abstract}
A autorregulação não é uma habilidade mental nem uma habilidade de performance acadêmica; antes, é um processo autodirigido, por meio do qual os aprendentes transformam suas habilidades mentais em habilidades acadêmicas. A aprendizagem é compreendida como uma atividade que os estudantes executam por si próprios, de maneira proativa, ao invés de um evento que acontece como reação a um processo de ensino. A autorregulação se refere, assim, a pensamentos, sentimentos e comportamentos autogerados, orientados para a consecução de objetivos.
\end{abstract}

A motivação é tida pelos autores acima referidos como um fator essencial para a autorregulação, podendo mostrar-se tanto como precursora, mediadora ou reforçadora da autorregulação. Embora seja mais comum nos referirmos à motivação como um constructo único, Zimmerman (2008) distingue diferentes fontes de motivação, que teriam papel diversificado no "disparar" e no mediar a autorregulação. São exemplos destas fontes: interesses pessoais, sentido de auto-eficácia, expectativas em relação aos resultados de uma ação/aprendizagem, perspectiva de futuro, o valor da ação a ser desempenhada, identidade cultural e de gênero e as mediações sociais. 
Um atributo-chave da autorregulação, nessa abordagem, acompanhando os trabalhos de Bandura, Azzi e Polidoro (2008), é o laço de retroalimentação pessoal, que se refere às informações quanto ao desempenho do sujeito, ao longo de um processo de aprendizagem, e que lhe permite realizar adaptações nesse processo. Conforme o modelo social cognitivo de autorregulação, defendido por Zimmerman e Campillo (2002), os laços de retroalimentação dos estudantes podem ser teorizados em 3 fases cíclicas, como pode ser observado abaixo:

Figura 1. Um modelo de fase cíclica da aprendizagem autorregulada

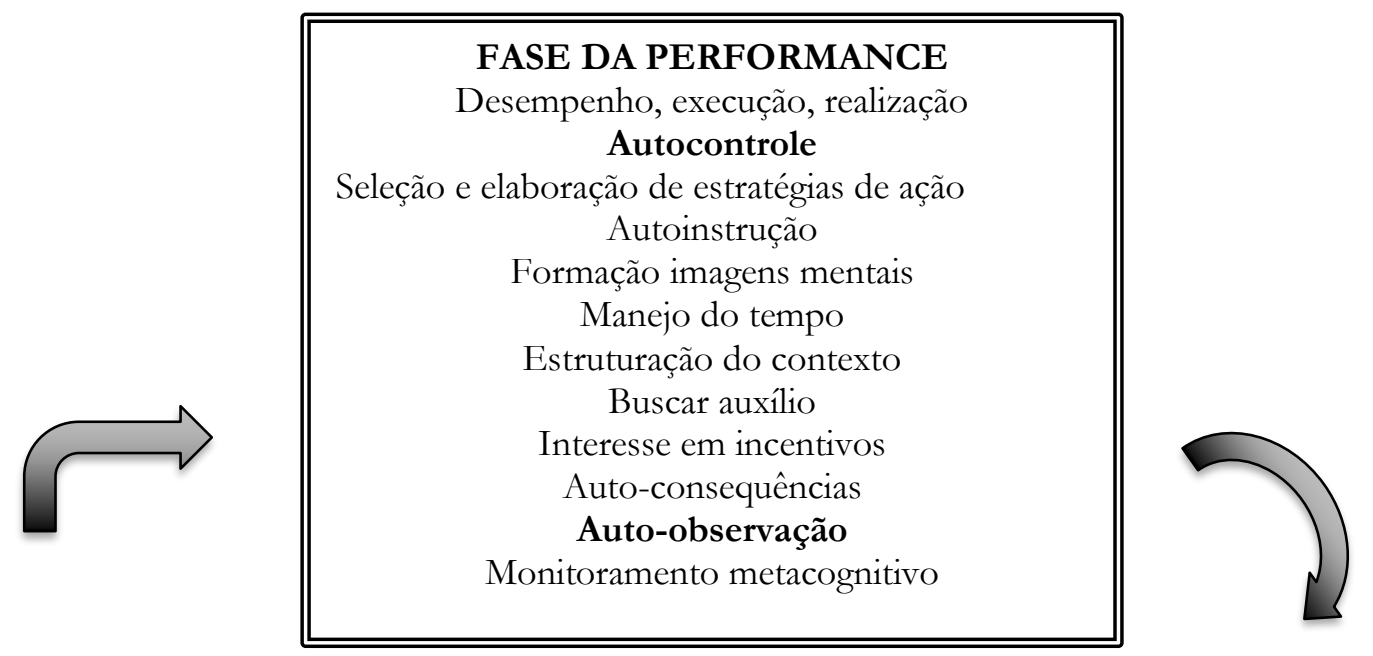

\begin{tabular}{||c||}
\hline FASE DO \\
PENSAMENTO \\
ANTECIPATÓRIO \\
(PLANIFICAÇÃO) \\
Análise da tarefa \\
Traçar objetivos \\
Planejamento estratégico \\
Crenças auto- \\
motivadoras \\
Auto-eficácia \\
Expectativas quanto aos \\
resultados \\
Valor e interesse da \\
tarefa \\
Orientação aos \\
objetivos/metas \\
\hline
\end{tabular}

FASE AUTOREFLEXÃO
Autojulgamento
Auto-avaliação
Atribuição causal
Auto-reação
Autossatisfação/afeto
Decisões
adaptativas/defensivas

Fonte: Zimmerman e Campillo (2002). 
Estas três fases dos laços de retroalimentação, nas quais estão envolvidas fontes motivacionais, estão no cerne da autorregulação, suportando-a: sem a presença de tais laços o próprio conceito perderia seu sentido. E devido a esta centralidade elegemos contemplar tais fases no questionário preparado para os estudantes do curso de Serviço Social. Essas fases estão mais bem explicitadas abaixo, acompanhando a argumentação de Zimmerman e Campillo (2002), tecendo-se considerações entre elas e os processos de aprendizagem dos estudantes da Educação Superior.

Destaca-se que as fases têm um caráter cíclico, ou seja, imbricam-se umas às outras, constituindo a dinamicidade do processo de autorregulação, não se colocando, dessa forma, a precedência de uma fase sobre a outra.

A fase do pensamento antecipatório se refere aos processos e origens da motivação, que precedem os esforços para aprender, afetando a preparação e a vontade para regular o próprio aprendizado. Zimmerman e Moylan (2009, p. 301) observam que essa fase é "composta por duas categorias principais: os processos de análise da tarefa e fontes de automotivação". Por análise da tarefa os autores entendem o processo de decompor aquilo a ser aprendido em unidades menores, sendo que o tratamento dado pelo aprendente a essas unidades estaria vinculado a dois outros sub-processos: aquele de traçar objetivos mais específicos para o aprendizado e o planejamento estratégico a ser adotado para aprender. Tal planejamento está coligado às condições que o estudante já desenvolveu para adaptar sua forma pessoal de aprender às especificidades do novo conhecimento, ao contexto de aprendizagem e às possíveis utilizações desse conhecimento. Em relação à automotivação, essa se mostraria constituída por vários outros sub-processos, como pressuposições de auto-eficácia pessoal e coletiva, inclusive aquelas envolvendo o status das categorias profissionais, expectativas em relação à aprendizagem em si e aos usos que poderão ser atribuídos a esta, tanto no plano pessoal como naquele profissional, interesse e valorização intrínsecas, vinculadas a determinada aprendizagem, e engajamento aos objetivos dessa, sendo importante para isto as crenças e sentimentos quanto aos propósitos subjetivos daquilo a ser aprendido.

Observa-se, contudo, que num processo de aprendizagem acadêmica formal, no qual há determinados componentes curriculares a serem aprendidos, nem sempre os objetivos de tais componentes correspondem àqueles de natureza mais subjetiva, próprios aos alunos. E mesmo o professor pode ter determinados objetivos a alcançar, com o ensino de determinada prática ou conteúdo, que não encontrem ressonância naqueles objetivos mais particularmente próprios aos alunos. Especialmente na Educação Superior, nível de ensino em que os estudantes já 
demonstram estarem mais conscientes de suas preferências e/ou necessidades de aprendizagem. A falta de emparelhamento entre os objetivos da aprendizagem curricular, os objetivos docentes e aqueles discentes pode impactar negativamente o desempenho do estudante e, consequentemente, os resultados da aprendizagem. Para um engajamento auto-motivacional que se sustente ao longo da aprendizagem é preciso que o estudante consiga identificar, para si, os potenciais "ganhos" que decorrerão desse aprendizado. E quanto mais esses ganhos forem percebidos como duradouros, ou seja, estendendo-se para além de uma funcionalidade momentânea (como ser bem-sucedido nos exames), mais se potencializaria a automotivação.

A percepção de auto-eficácia- crença na própria capacidade de aprender ou executar ações em determinado nível- tem sido associada à identificação dos objetivos e da seleção de estratégias dos estudantes para alcançá-los (MARGOLIS, McCABE, 2006). Pode afetar a fase da performance diretamente, influenciando as escolhas das atividades nas quais a pessoa se engaja, seus esforços e persistência para realizá-las. As percepções de auto-eficácia de um estudante podem afetar suas estratégias de aprendizagem em diversas áreas, tais como leitura/escrita, organização do tempo, resistência a pressões adversas e auto-monitoramento durante a realização das atividades.

Uma segunda fonte de automotivação está nas expectativas dos estudantes em relação aos resultantes de determinada ação formativa, referindo-se às crenças quanto aos fins últimos da própria performance, tais como receber reconhecimento social ou conseguir melhores condições de empregabilidade. Tais expectativas dependem do seu conhecimento ou da sua concepção quanto às "recompensas" que podem advir do aprendizado, da preparação profissional, e do que é percebido como impulso à formação pessoal. Dentre essas se colocam os potenciais salários, mudança na qualidade de vida, melhor enfrentamento dos desafios cotidianos, benefícios sociais - para si e também para a coletividade-, dentre outros.

A motivação dos estudantes, então, para regular sua aprendizagem pode ser influenciada por múltiplos motivos, tais como crenças de auto-eficácia e expectativas em relação aos resultantes da aprendizagem e da ação (in)formativa da Educação Superior. Uma terceira fonte de motivação nesta fase do ciclo está no interesse e valor atribuídos às tarefas de aprendizagem em si. Refere-se a se o estudante aprecia ou não essas tarefas devido às suas propriedades inerentes, sendo que essa apreciação pode influenciar as escolhas quanto ao que estudar. Um estudante que valoriza atividades que favorecem o contato com a natureza pode se afastar de tarefas de aprendizagem que exijam muito tempo de aplicação dentro da sala de aula, por exemplo. Uma quarta fonte de motivação é a determinação dos estudantes direcionada a uma 
meta, o que envolve suas crenças ou sentimentos em relação aos propósitos da sua própria aprendizagem.

Já a fase da performance (do desempenho ou da execução) envolve os processos que acontecem durante a aprendizagem, e afetam a concentração, a perseverança nos objetivos e a consecução da tarefa em si. Abarca o autocontrole e a auto-observação. A auto-observação, fundada sobre o monitoramento metacognitivo, desempenha um papel central nos esforços dos estudantes para autorregular sua performance. Estratégias de autocontrole envolvem autoinstrução, formação de imagens mentais organizadoras dos conteúdos a serem aprendidos, controle do tempo, estruturação do ambiente, identificar as próprias necessidades de aprendizagem e saber quando e como buscar ajuda, incentivos para manter-se motivado e a autoimposição de consequências, relacionadas ao desempenho para aprender.

A fase da reflexão engloba os processos que acompanham os esforços para aprender, voltando-se principalmente para as reações do aprendente à experiência de aprendizagem. É integrada por percepções de auto-avaliação e de atribuição causal às ações realizadas pelo estudante, durante o processo de aprendizagem. E também por aquelas de auto-reação, que se desdobram em autossatisfação, ou considerações de afeto em relação ao aprendizado, ou na busca por evitar situações de desconforto afetivo ou emocional, decorrentes desse. Como estudar para evitar uma reprovação, por exemplo. As reações afetivas e emocionais envolvidas nos processos de aprendizagem podem, por sua vez, influenciar positiva ou negativamente as decisões posteriores do estudante para interessar-se ou motivar-se para o engajamento num novo ciclo de aprendizagem. Se positivas, o estudante iniciará esse novo ciclo mantendo as estratégias já desenvolvidas ou adaptando-as. Se negativas, ele poderá desenvolver reações defensivas à aprendizagem, para evitar prováveis insatisfações e afetos aversivos. A procrastinação, o desengajamento cognitivo e a apatia em relação ao aprender são formas de comportamento defensivo. As auto-reações influenciam o pensamento antecipatório, levando o estudante a calibrar sua percepção de auto-eficácia, a dedicação para aprender, o desenvolvimento de estratégias cognitivas e de organização pessoal, e a proposição de outros objetivos e metas para a aprendizagem.

\section{Da apresentação e análise dos dados}

Como dito anteriormente, o questionário aplicado aos alunos do curso de Serviço Social foi elaborado com base nas fases do processo de autorregulação, como teorizado por Zimmerman e colaboradores. A seguir descreve-se, então, as categorias correspondentes a cada 
uma das fases do Modelo Cíclico de Aprendizagem Autorregulada e as questões, nessas fundamentadas, estruturadas para a averiguar a percepção dos estudantes quanto aos processos e desempenho nas tarefas de aprendizagem associadas à participação no "Projeto".

Inicia-se, abaixo, com os quesitos direcionados a levantar dados sobre a fase do pensamento antecipatório, especialmente em relação ao componente de "crenças automotivadoras", importante nos esforços desenvolvidos pelos alunos para completar sua formação na Educação Superior. Esse componente foi, por sua vez, abordado pela percepção de auto-eficácia, do valor e do interesse das tarefas de aprendizagem, desenvolvidas ao longo da pesquisa, em relação à prática profissional. O primeiro estamento colocado aos alunos foi:

1. Participar da investigação no "Projeto" tem influenciado minha crença na capacidade de ser um/uma profissional qualificado/a.

As respostas a esse estamento mostraram que $62 \%$ dos estudantes concorda com a afirmação, 33\% concorda plenamente e 5\% não concorda, nem discorda. A questão aberta associada a esse estamento indagava como os estudantes percebiam que a participação no "Projeto" havia influenciado (ou não) as suas expectativas em relação à qualificação profissional.

As respostas a essa questão foram agrupadas em cinco categorias, de acordo com as semelhanças enunciadas nos teores, sendo que $4 \%$ dos estudantes afirmou que a participação no "Projeto" possibilitou confiança na construção de argumentação para intervir nas problemáticas encontradas, $6 \%$ associou-a ao desenvolvimento de processos cognitivos, como observar e criar hipóteses sobre diversas formas de solucionar problemas, $13 \%$ que ajudou a manter o foco nos estudos, com dedicação e responsabilidade, combinando isso à seriedade da prática profissional, 24\% referiu-se à ampliação do nível de conhecimentos para compreender a realidade e a habilidade de trabalhar em grupos e 53\% à formação profissional mais qualificada, que permitirá tomar providências mediante as situações estudadas/pesquisadas.

Em relação ao valor e interesse da tarefa o estamento foi assim colocado:

2. Participar da investigação no "Projeto" tem influenciado minha compreensão quanto aos objetivos da aprendizagem teórica na graduação em Serviço Social.

Concordaram com essa afirmação $71 \%$ dos respondentes, sendo que $24 \%$ concorda plenamente e 5\% não concorda, nem discorda. Para entender os desdobramentos dessas respostas propusemos uma questão aberta, que se direcionava a saber se a participação no Projeto influenciava a compreensão quanto aos objetivos da aprendizagem teórica do Serviço Social. As respostas, também sintetizadas pelas semelhanças discursivas, indicaram que para 
$30 \%$ dos respondentes a participação no "Projeto" colaborou para melhor compreender os teóricos e aprimorar o raciocínio, para outros $25 \%$ despertou o entendimento da importância da teoria para a prática profissional e a compreensão da realidade, o que colabora para o aprendizado teórico. Declararam que o "Projeto" destaca o papel do assistente social na sociedade $15 \%$ dos alunos, sendo que também $15 \%$ afirmaram que os temas investigados envolviam dilemas que terão que ser enfrentados na prática profissional, e 10\% associaram a participação no "Projeto" ao aprendizado para usar corretamente diversas ferramentas de pesquisa, agilizando os estudos e colaborando para outras pesquisas, como os trabalhos de conclusão de curso (TCC). E para 5\% as diversas disciplinas têm seus próprios objetivos, não estabelecendo relações entre esses e as investigações desenvolvidas no "Projeto".

A fase do pensamento antecipatório é crucial para o aluno ponderar sobre suas capacidades ao desempenhar determinada tarefa de aprendizagem, bem como para estabelecer objetivos e estratégias para atingi-los. Como dito anteriormente, os seguintes subcomponentes destacam-se aqui: os critérios de (auto)avaliação e o nível de desempenho necessário para atingir tais critérios. Consideramos, com base nas respostas dos alunos, que a participação no "Projeto" colaborou para a tomada de consciência quanto as especificidades da profissão e das competências e habilidades necessárias para desempenhá-las. Isso foi favorecido pela aproximação entre os temas da pesquisa e o contexto profissional, facilitando ao aluno perceber que a identidade e o perfil profissional são construídos processualmente, ao longo da graduação, e após essa. A ação investigativa, em suas diferentes fases, possibilitou ao graduando colocarse sub-objetivos em seu processo formativo (desenvolver habilidades para a leitura de textos complexos, para redigir documentos de caráter científico, para expressar-se e argumentar oralmente, assumir o raciocínio próprio à carreira de assistente social, dentre outros), ao mesmo tempo disponibilizando meios para avaliar a qualidade desse desenvolvimento, pela confrontação com os critérios de exigência associados a tais sub-objetivos: a aprovação dos trabalhos submetidos a eventos acadêmicos, a apresentação de pôsteres e comunicações orais, a troca com os demais grupos de pesquisa, pensar em recursos técnicos que pudessem responder às problemáticas pesquisadas e sua viabilidade, e as intervenções do professor-orientador.

A percepção da "utilidade" do conhecimento teórico para a transformação da vida social e para a formação do profissional foi estimulada pelas problemáticas das pesquisas, e favoreceu o interesse e a valoração positiva dos esforços destinados a concluí-las, revertendo-se também em mais empenho para concluir a formação profissional. Para Panadero e Alonso-Tapia (2014), quando os estudantes avaliam uma tarefa de aprendizagem como "útil", sua motivação para 
desempenhá-la aumenta. E recomendam que os professores, ao introduzirem uma nova aprendizagem, o façam de forma a que os estudantes percebam a utilidade do conteúdo que será trabalhado. Observamos, entretanto, que o critério de "utilidade" perde sua força motivacional se for "artificial", ou seja, se predominantemente fundado sobre expectativas do docente, sem considerar aquelas dos estudantes. Como o "Projeto" propõe o estudo de determinadas questões a partir dos interesses dos próprios alunos, há uma relação de identidade entre a "utilidade" da aprendizagem e do conhecimento e o objeto de estudo; ampliando a motivação para o desempenho.

Para avaliar as concepções dos estudantes sobre a fase da performance foram propostos quesitos voltados ao desenvolvimento de estratégias para a aprendizagem acadêmica. $\mathrm{O}$ estamento colocado foi:

\section{Participar da investigação no "Projeto" tem tido influência em minhas estratégias para} estudar.

Dentre os respondentes $71 \%$ afirmaram concordar com esse estamento, e outros $29 \%$ concordaram plenamente.

A questão aberta se direcionou a indagar de que forma (se alguma) a participação no "Projeto" tinha colaborado para tanto, procurando-se identificar, nos teores das respostas, os seguintes componentes, fundamentais da fase da performance: o desenvolvimento de estratégias de auto-observação, de monitoramento metacognitivo e de autocontrole.

As respostas evidenciaram que para $29 \%$ dos alunos a participação no "Projeto" potencializou o pensamento crítico e investigativo, promovendo a observação e a atenção para situações que passavam despercebidas. Para outros $24 \%$ destacou-se um maior aprofundamento nos assuntos estudados, e ter mais ideias e conhecimentos sobre o tema. Outros 14\% afirmaram ter mais interesse, dedicação e vontade de estudar sobre o tema escolhido, sendo que também 14\% declararam ter criado estratégias de leitura, conseguindo ter uma capacidade de interpretação textual de melhor qualidade. Já $10 \%$ dos alunos fez referência a ter mais organização para os trabalhos e atividades escolares e para pesquisar, passando a entender a pesquisa como projeto acadêmico, e outros $8 \%$ que desenvolveram recursos para realizar atividades de pesquisa, aprendendo a buscar dados e estatísticas selecionados de fontes confiáveis.

O desenvolvimento de estratégias de autocontrole, componente importante para a determinação motivacional em continuar os estudos, foi explorado a partir do estamento:

“4. Participar do "Projeto" tem influenciado meus esforços para me formar como assistente social", ao qual $48 \%$ dos estudantes responderam que concordam plenamente, $38 \%$ que Barbarói, Santa Cruz do Sul, n. 57, p.<218-238>, jul./dez. 2020 
concordam e $14 \%$ que não concordam, nem discordam. A questão aberta associada a esse estamento era: "Justifique sua resposta". Encontramos então que $30 \%$ dos respondentes considera que descobriu razões para aprender mais, para ter uma formação mais atualizada, podendo intervir melhor nas questões sociais, outros $30 \%$ afirmaram que passaram a entender a importância da pesquisa e dos conhecimentos especializados para o Serviço Social, motivando-se para a aprendizagem desses. Outros 15\% afirmaram que perceberam como as funções desempenhadas pelo assistente social são importantes para a melhoria da realidade social e que se sentiam com mais vontade para dedicarem-se à conclusão dos estudos, mesma porcentagem daqueles que afirmaram terem tido maior identificação com a profissão, e sentimento de realização com a escolha profissional, enquanto $10 \%$ asseveraram não terem visto relação entre os temas estudados e o Serviço Social.

$\mathrm{Na}$ fase da performance, ou do desempenho, a autorregulação se processa pela autoobservação e o autocontrole. A auto-observação favorece que o aprendente tenha a compreensão mais clara possível sobre a pertinência e a qualidade de suas ações, frente aos objetivos desejados com determinada aprendizagem, direcionando os ajustes que devem ser feitos para que essa seja bem-sucedida. Constitui-se numa atividade metacognitiva. No autocontrole há o emprego de uma série de estratégias para que o aprendente se mantenha concentrado e interessado na aprendizagem. Dentre essas estratégias estão a autoinstrução, que pode ser efetivada pelo fazer perguntas a si mesmo, ou rememorar a descrição de certo conteúdo acadêmico; o uso de imagens mentais, como os mapas conceituais, ou ilustrar o que está sendo estudado com figuras e/ou esquemas; o gerenciamento do tempo, incluindo a elaboração de sub-estratégias para chegar ao resultado desejado; regular o nível de distrações do ambiente; identificar as próprias fragilidades no processo de aprendizagem e buscar o auxílio do professor ou de colegas mais adiantados para superá-las e reconhecer o que tem sido feito corretamente, mantendo a motivação pelo auto-incentivo. A criação dessas estratégias foi estimulada pelo processo de pesquisa, pois nas várias fases dessa foram promovidas oportunidades para que os alunos experimentassem e encontrassem diversas maneiras de lidar com a informação e organizá-la, conscientizando-se sobre quais dessas estratégias mais bem se adequava aos seus estilos de aprendizagem.

A participação no "Projeto" mostrou-se relevante para o desenvolvimento tanto da autoobservação como do autocontrole. O engajamento dos participantes com a pesquisa, reconhecendo a importância da construção de uma base teórica para o entendimento da complexidade das situações estudadas e daí para a elaboração de intervenções que se 
mostrassem bem sucedidas, mobilizou o gerenciamento do tempo, bem como de estratégias para o controle da atenção e da motivação. E também daquelas que promoveram o controle emocional, importantes para superar os momentos de "desencanto" ou de um estado de humor "negativo" em relação aos desafios e as dificuldades de várias ordens, próprias a um processo de investigação (demandas cognitivas, cansaço, problemas na interação grupal, questionamento de perspectivas de compreensão da realidade, dentre outras). O contínuo processo de construção e reconstrução dos dados, e de reelaboração do substrato teórico da pesquisa, favoreceu também a compreensão de que os erros abrem oportunidades para um melhor aprendizado.

A análise da fase da autorreflexão foi buscada pelo estamento:

5. Participar da investigação no "Projeto" tem influenciado minha organização $e$ autocontrole para estudar.

As respostas indicaram que $57 \%$ concorda, $29 \%$ nem concorda, nem discorda, $8 \%$ concorda plenamente e $6 \%$ não concorda. $\mathrm{O}$ desdobramento dessas respostas se pautou no entendimento das atribuições causais, provenientes do autojulgamento, que fazemos sobre as razões para o nosso desempenho pessoal, tais como habilidades que empregamos, esforço e uso de estratégias para alcançar os objetivos propostos. Nesse sentido, 22\% dos alunos afirmaram ter desenvolvido disciplina e rotina para estudar, $22 \%$ consideraram que têm uma forma própria de estudar e que essa não se alterou com a participação no "Projeto", e outros $22 \%$ disseram que a participação no "Projeto" facilitou estudar, pois desenvolveram técnicas para trabalhar com uma quantidade maior de informações. Para $17 \%$ houve uma melhora na organização para os estudos, de forma geral, $11 \%$ destacaram uma melhor organização do tempo dedicado aos estudos e $6 \%$ consideraram que nem todos os membros do grupo se empenharam para realizar as atividades necessárias à pesquisa.

Nessa fase há uma apreciação do aprendente quanto aos resultantes do seu processo de aprendizagem, acompanhada por autojustificativas e atribuições causais referentes ao que foi considerado como "sucesso" ou "insucesso", e sentimentos afetivos "positivos" ou "negativos". Todo esse conjunto de julgamentos quanto à própria performance influenciará o engajamento do aprendente em outros processos de aprendizagem, bem como a autorregulação em si.

Em relação ao aprendizado ao longo do processo de pesquisa as possibilidades de autojulgamento e de auto-avaliação foram favorecidas pelos critérios de validação e de confiabilidade dos dados, bem como do conhecimento construído. A avaliação discente se afastou, dessa forma, do plano da heteronomia para aquele da autonomia, impulsionando a reflexão dos alunos quanto ao avanço do seu próprio desenvolvimento, enquanto aprendente. 
Observa-se que a fase da reflexão é composta também pelo estabelecimento de comparações entre os objetivos postos pelo próprio aprendente à aprendizagem em questão, suas concepções quanto às suas qualidades como aluno (formada pelo histórico de suas aprendizagens) e o desempenho demonstrado pelos outros sujeitos envolvidos com o contexto da aprendizagem. Dependendo das comparações estabelecidas o resultado da fase de reflexão pode se diferenciar. Dessa forma, é importante favorecer oportunidades para que os alunos possam estabelecer diversas perspectivas de análise e julgamento do seu desempenho. Assim se promoverá possibilidades para que haja um menor número de decisões defensivas em relação a novas aprendizagens, ou seja, evitando-se que o aluno desenvolva o temor por envolver-se em outras situações de aprendizagem, por recear ser malsucedido. As respostas dos estudantes do Serviço Social, ao destacarem o desenvolvimento de estratégias de estudo e de formas de aprender, evidenciaram uma motivação para encarar novos aprendizados, o que pode estar associada às diferentes ocasiões para avaliar e corrigir os rumos do próprio processo de aprendizagem favorecidas pela vinculação ensino e pesquisa.

Um último aspecto a ser aqui analisado se refere à influência do comportamento do grupo na motivação e na autorregulação. Para 90\% dos estudantes o apoio do grupo com o qual a pesquisa é desenvolvida exerce influência na motivação e na autodeterminação em concluir tanto os procedimentos investigativos como o próprio curso de graduação. Outros $10 \%$ discordam, não considerando relevante o papel do grupo nesses processos. Ao serem indagados sobre quais as formas assumidas por essa influência $47 \%$ dos alunos afirma que a organização do grupo e a integração entre os seus membros auxilia na execução das atividades da pesquisa e nos estudos desenvolvidos no curso de graduação. Para 32\% dos respondentes o grupo exerce um papel motivador para o empenho nos trabalhos acadêmicos, $16 \%$ consideram que a relevância dos temas pesquisados foi importante para o entrosamento do grupo, resultando na criação de um ambiente de colaboração para a investigação e 5\% percebem o trabalho em grupo como forma de pressão para o desenvolvimento das atividades.

De acordo com Finkel e Fitzsimons (2011), as interações sociais afetam três dos principais componentes da autorregulação: a proposição de objetivos e metas, os esforços para a sua consecução e o monitoramento do desempenho, podendo ter efeitos positivos ou negativos sobre esses. Na fase da proposição de objetivos e metas os autores argumentam que as pessoas se propõem objetivos, e iniciam ações para alcançá-los, influenciadas pela sua participação em determinado grupo. $\mathrm{Na}$ fase de desempenho e de monitoramento o papel do grupo tem sido associado com o provimento de suporte social e afetivo-emocional, contribuindo para a 
perseverança na tarefa e na motivação para levá-la a bom termo. Järvelä et. al. (2013) também destacam a importância do grupo na autorregulação, considerando que a aprendizagem é regulada de maneira socialmente compartilhada, pela negociação de significados, objetivos e metas comuns e pelo suporte que os membros do grupo dão uns aos outros na superação das dificuldades e na atribuição de um sentimento de positividade afetiva à aprendizagem.

\section{Considerações finais}

Pretendemos, nesse artigo, analisar se o uso da pesquisa como metodologia de ensino na Educação Superior pode contribuir para o desenvolvimento de processos cognitivos importantes para a formação pessoal e profissional dos estudantes. A partir da apreciação das respostas coletadas nos questionários considera-se que um dos aspectos mais relevantes da vinculação ensino-pesquisa, proposta no "Projeto", esteve na atribuição positiva de sentido ao processo de aprendizagem, por parte dos estudantes. Tal positividade se refere tanto ao desenvolvimento de um sentido de agência, manifestada num comportamento proativo dos graduandos para desenvolver estratégias cognitivas e afetivo-emocionais, que favoreceram o aprendizado, como da automotivação.

Em relação às três questões que pretendiam ser aqui respondidas pode-se afirmar que o "Projeto", mostrou-se uma possibilidade para desenvolver os processos de autorregulação, colaborando para que o estudante se tornasse mais autônomo ao reger sua aprendizagem, criando ou adaptando estratégias para organizar seu tempo e outras habilidades necessárias ao meio acadêmico, e, importantemente, desenvolvendo uma curiosidade epistêmica em relação às especificidades da atuação profissional, no caso, aquela do assistente social.

A possibilidade aberta aos alunos para selecionarem o objeto de pesquisa de acordo com suas inquietações pessoais, em combinação com aquelas do seu grupo de trabalho, foi um fator importante na fase do pensamento antecipatório, propagando-se para as demais fases do ciclo autorregulatório. A identificação com questões pertinentes à prática profissional, favorecidas pelos temas da pesquisa, mostrou-se relevante para a determinação pessoal no objetivo de graduar-se como assistente social. Destaca-se também o desenvolvimento da construção da identidade profissional, apontando que o processo de pesquisa pode ser um diferencial no tipo de reflexões feitas pelos alunos em relação à própria profissão, favorecendo um olhar problematizador sobre essa.

Finalmente, há que se considerar a importância que o grupo de trabalho teve durante todo o processo de ensino e pesquisa, colaborando para a motivação e a regulação individual e 
coletiva. A influência do grupo mostrou ter impactos que se estenderam do auxílio para superar dificuldades acadêmicas ao suporte emocional e ao estímulo para continuar os estudos. Além disso, foi relevante na atribuição de sentimentos positivos ao processo de aprendizagem, o que pode contribuir para a prevenção de comportamentos defensivos em outros ciclos de aprendizagem. É um fator que pode receber maior atenção e aprofundamento teórico na proposição de estratégias didáticas na Educação Superior.

A busca por outras formas de desenvolver metodologias didáticas na Educação Superior tem se colocado como necessidade frente aos complexos desafios postos à sociedade atual e à Universidade, locus de produção e promoção do conhecimento para o enfrentamento de tais desafios. O ensino como pesquisa aponta caminhos promissores para a inovação didáticometodológica nesse nível de ensino, favorecendo ao mesmo tempo uma formação teóricoprática rigorosa, em termos de qualidade científica, e a consciência do futuro profissional quanto à sua importância para o desenvolvimento sociocultural e econômico de sua comunidade.

\title{
TEACHING AS RESEARCH AND THE DEVELOPMENT OF SELF-REGULATION IN HIGHER EDUCATION: A STUDY IN SOCIAL SERVICE GRADUATION
}

\begin{abstract}
The objective of the study is to evaluate if the alignment between teaching and research, as didactically proposed under an undergraduate degree in Social Work, has brought contributions to two key components to academic learning and successful professionals: self-regulation and motivation. Methodologically, we seek to draw comparisons enters the characteristics of this didactic proposition and a cyclical model of self-regulation of learning, employing as data collection instrument a semi-structured questionnaire administered to students in that course. As a result we can say that the development of educational and teaching methods based on teaching and research association was shown to be relevant for students to draw up cognitive strategies to manage, interpret and organize information, contributed to better management of time spent for academic activities, mobilized awareness of the construction of professional identity, influencing the determination to finish school and the motivation to be successful. We underline the importance that the group has on the development of self-regulation and motivation, aspects that may be more extensive in the discussions on new methodologies for Higher Education.
\end{abstract}

Keywords: Self-regulation. Higher education. Teaching as research.

\section{LA ENSEÑANZA COMO INVESTIGACIÓN Y EL DESARROLLO DE LA AUTORREGULACIÓN EN LA EDUCACIÓN SUPERIOR: UN ESTUDIO EN LA GRADUACIÓN DE SERVICIO SOCIAL}

\section{Resumèn}

El objetivo del estudio es evaluar si la alineación entre la enseñanza y la investigación, como didácticamente propuesta en un título de grado en Trabajo Social, ha traído contribuciones a 
dos componentes fundamentales para el aprendizaje académico y profesionales de éxito: la autorregulación y la motivación. Metodológicamente, trata de hacer comparaciones entra en las características de esta propuesta didáctica y un modelo cíclico de la autorregulación del aprendizaje, se emplea como instrumento de recolección de datos un cuestionario semiestructurado administrado a los estudiantes en ese curso. Como resultado, creemos que se puede afirmar que el desarrollo de métodos educativos y de enseñanza basado en la enseñanza y la investigación demostró asociación importante para los estudiantes que elaboren estrategias cognitivas para gestionar, interpretar y organizar la información, contribuimos a una mejor gestión del tiempo para las actividades académicas, movilizó la conciencia y de la construcción de la identidad profesional, que influyen en la determinación de terminar la escuela y la motivación para tener éxito. Subrayamos la importancia de que el grupo ejerce sobre el desarrollo de la autorregulación y la motivación, aspectos que pueden ser más profundidad en las discusiones sobre nuevas metodologías para la Educación Superior.

Palabras clave: Autorregulación. Ensino Superior. La enseñanza como investigación.

\section{REFERÊNCIAS}

BALL, I.; PERRY, C. Differences in Student Engagement: Investigatin the Role of the Dominant Cognitive Process Preferred by Engineering and Education Students. Education Research International, v. 2011, article ID 414068, 8 pages.

BANDURA, A.; AZZI, R.; POLYDORO, S. Teoria Social Cognitiva: conceitos básicos. Porto Alegre: Artmed, 2008.

BAUMEISTER, R. F.; VOHS, K. D.; TICE, D. M. The Strength Model of Self-Control. Current Directions in Psychological Science, v. 16, n. 351, 2007.

https://doi.org/10.1111/j.1467-8721.2007.00534.x

BERNHARDT, V. Data analysis for continuous school improvement. New York: Routledge, 2013.

BRASIL. Plano Nacional de Educação. Brasília, Presidência da República, lei n. 13005 de 25 jun de 2014. Disponível em: http://www.planalto.gov.br/CCIVIL_03/_Ato20112014/2014/Lei/L13005.htm acesso em 20 jul 2014.

BRYMAN, A. Social Research Methods. UK: Oxford University Press, 2008.

CURY, C. R. J. Por um sistema nacional de Educação. São Paulo: Moderna, 2010.

EHLERS, U-D. Future Skills: The Future of Learning and Higher Education. Germany: Kalrsruhe, 2020.

FITZSIMONS, G.M.; FINKEL, E. J. Outsourcing Self-Regulation. Psychol Sci, 22 (3), p. 369-75, mar 2011. https://doi.org/10.1177/0956797610397955

FREIRE, P. Educação "bancária” e Educação Libertadora. In: PATTO, M. H. S. (org). Introdução à Psicologia Escolar. 3 e. São Paulo: Casa do Psicólogo, 1997.

GUEDES, M. D.; MURANAKA, M. A.; ARAGÃO, J. E. Avaliação na Educação Superior no Brasil: uma análise dos seus fundamentos. In Coloquio de Gestión Universitaria en Américas, 13, 2013, Florianópolis. Anais...Florianópolis, 2013, p. 11-27.

Barbarói, Santa Cruz do Sul, n. 57, p.<218-238>, jul./dez. 2020 
GRIFFIOEN, D. M.; GROEN, A., NAK, J. The Integration of Research in the Higher Education Curriculum: A Systematic Review. The Higher Education Journal of Learning and Teaching, 10(1), 2019. https://doi.org/10.24384/vhs6-1j85

JÄRVELÄ, S.; JÄRVENOJA, H.; MALMBERG, J.; HADWIN, A. Exploring Socially Shared Regulation in the Context of Collaboration. Journal of Cognitive Education and Psychology, v. 12, n. 03, p. 267-286, 2013.

JENKINS, A. A guide to the Research Evidence on Teaching-Research Relations. UK: The Higher Education Academy, 2004.

MARGOLIS, H.; McCABE, P. Improving Self-Efficacy and Motivation: What to Do, What to Say. Intervention in School and Clinic, v 41 issue 4, p. 218-227, mar 2006.

MILLER, A.; DUMFORD, A. Cognitive Creative Processes in Higher Education. The Journal of Creative Behavior, nov 2014. https://doi.org/10.1002/jocb.77

PANADERO, E.; ALONSO-TAPIA, J. How do students self-regulate? Review of Zimmermans cyclical model of self-regulated learning. Anales de Psicología, v. 30, n. 02, p. 450-462, mai 2014.

PESSOA DE FREITAS, P.; MONTEZANO, L.; ODELIUS, C. A influência de atividades extracurriculares no desenvolvimento de competências gerenciais em grupos de pesquisa. Administração: Ensino e Pesquisa, v. 20, Ed. 01, p. 1-25, Jan-Abr 2019.

https://doi.org/10.13058/raep.2019.v20n1.1070

TIGHT, M. Researching Higher Education. UK: McGraw-Hill Education, 2012.

THOMPSON, R. Beyond Reason and Tolerance: The Purpose and Practice of Higher Education. UK: Oxford University Press, 2014.

ZIMMERMAN, B. J. Attaining self-regulation: A social-cognitive perspective. In: BOEKAERTS, M.; PINTRICH, P.; SEIDNER, M. (Eds.). Self-regulation: Theory, research, and applications. Orlando, FL: Academic Press, 2000. pp. 13-39.

.; CAMPILLO, M. Motivating self-regulated problem solvers. In: DAVIDSON, J. E.; STERNBERG, R. J. (Eds.) The nature of problem solving. New York: Cambridge University Press, 2002.

Investigating Self-Regulation and Motivation: Historical Background, Methodological Developments, and Future Prospects. American Educational Researcher, v. 45, n. 166, 2008.

; MOYLAN, A. R. Self-regulation: Where metacognition and motivation intersect. In HACKER, D. J.; DUNLOSKY, J.; GRAESSER, A. C. (Eds.). Handbook of Metacognition in Education. New York: Routledge, 2009. pp. 299-315.

; SCHUNK, D. H. Handbook of self-regulation of learning and performance. New York: Routledge, 2011. 
Data de recebimento: 03/08/2015

Data de aceite: $22 / 10 / 2019$

\section{Sobre as autoras:}

Maria Luisa Bissoto é Doutora e Pós-doutora em Educação. Área de pesquisa: processos cognitivos e educação. Endereço Eletrônico: profamalucosta@gmail.com

Maria Isabel Vicente é Assistente Social, coordenadora do curso de graduação e de pósgraduação em Serviço Social do Centro Universitário Salesiano de São Paulo (UNISAL), campus Maria Auxiliadora. Endereço Eletrônico: maria.vicente@ unisal.br 